\title{
AS CANÇÕES ITALIANAS INTERPRETADAS POR RENATO RUSSO ${ }^{1}$
}

\author{
Paolo Torresan ${ }^{2}$
}

\section{Resumo}

Quais são os autores italianos que seduzem Renato Russo? Quais são os temas tratados em suas canções? Podemos formular um juízo acerca da qualidade literária nas letras das músicas? Há nas canções interpretadas por ele, indícios que nos falam da Itália dos anos 80 e 90?*

Palavras-chave: Renato Russo, Música Pop Italiana, Literatura, Cultura italiana.

\begin{abstract}
From which authors does Renato Russo take inspiration? What themes does he consider? Can we formulate judgements regarding the literary quality of his texts? Do his songs offer insights into 80s and 90s Italy?
\end{abstract}

Keywords: Renato Russo, Italian Popular Music, Literature, Italian Culture

\section{Autores, cantores e canções}

Grande parte das canções italianas interpretadas por Renato Russo estão no álbum Equilíbrio distante, o qual também apresenta uma versão em italiano e

\footnotetext{
${ }^{1} \mathrm{O}$ autor agradece à Maria da Penha Souza pela tradução e revisão do artigo

${ }^{2}$ Laboratorio Itals - Università Ca’ Foscari, Venezia. E-mail: esh@unive.it
} 
outra em inglês da música 'Como uma Onda' de autoria de Lulu Santos ${ }^{3}$. O Último Solo (1997), álbum lançado postumamente, possui canções inglesas e italianas. No que diz respeito a essas últimas, é possível notar uma interpretação menos cuidadosa, uma vez que, a exemplo do que ocorre com a canção Il Mondo degli altri, de Baldi, evidenciam-se numerosos erros fonéticos e prosódicos. Há rumores de que Renato Russo não tinha a intenção de lançar esse álbum e que ele teria sido gravado de forma experimental.

A tabela abaixo apresenta as canções com título, intérprete, autor e tema principal.

\begin{tabular}{|c|c|c|c|}
\hline INTÉRPRETE & $\begin{array}{c}\text { CANÇÕES } \\
\text { INTERPRETADAS }\end{array}$ & MÚSICA E LETRA & TEMA \\
\hline \multirow{4}{*}{ LAURA PAUSINI } & Strani amori & $\begin{array}{l}\text { A. Valsiglio, } \\
\text { R. Butti, } \\
\text { Cheope, } \\
\text { M. Marati }\end{array}$ & $\begin{array}{l}\text { A decisão de } \\
\text { interromper um } \\
\text { relacionamento que } \\
\text { cria indecisões. }\end{array}$ \\
\hline & La solitudine & $\begin{array}{l}\text { P. Cremonesi, } \\
\text { A. Valsiglio, } \\
\text { F. Cavalli }\end{array}$ & $\begin{array}{c}\text { A sensação de } \\
\text { abandono, depois da } \\
\text { partida do ser amado. }\end{array}$ \\
\hline & Lettera & $\begin{array}{l}\text { A. Valsiglio, } \\
\text { G. Salvatore, } \\
\text { Cheope, } \\
\text { M. Marati }\end{array}$ & $\begin{array}{c}\text { Uma declaração } \\
\text { revelada em uma } \\
\text { carta, dada a } \\
\text { dificuldade de } \\
\text { exprimir os } \\
\text { sentimentos } \\
\text { oralmente. }\end{array}$ \\
\hline & Gente & $\begin{array}{l}\text { A. Valsiglio, } \\
\text { Cheope, } \\
\text { M. Marati }\end{array}$ & $\begin{array}{c}\text { A esperança de } \\
\text { alcançar a serenidade, } \\
\text { apesar dos erros que } \\
\text { se cometem }\end{array}$ \\
\hline
\end{tabular}

${ }^{3}$ Italiano - Come fa un'onda ; Inglês - Wave 


\begin{tabular}{|c|c|c|c|}
\hline & & & cotidianamente. \\
\hline FIORELLA MANNOIA & $\begin{array}{l}\text { I venti del } \\
\text { cuore }\end{array}$ & $\begin{array}{l}\text { M. Bubbola, } \\
\text { P. Fabrizi }\end{array}$ & $\begin{array}{l}\text { Um lugar que traz a } \\
\text { recordação de uma } \\
\text { pessoa amada. }\end{array}$ \\
\hline NINO BONOCORE & Scrivimi & N. Bonocore & $\begin{array}{l}\text { A esperança de que a } \\
\text { pessoa amada } \\
\text { mantenha contato, } \\
\text { mesmo que só através } \\
\text { da escrita. }\end{array}$ \\
\hline \multirow[t]{2}{*}{ Claudio Baglioni } & $\begin{array}{l}\text { La vita è } \\
\text { adesso }\end{array}$ & C. Baglioni & $\begin{array}{c}\text { Viver cada momento } \\
\text { em contato com } \\
\text { experiências e } \\
\text { emoções. }\end{array}$ \\
\hline & E tu come stai & C. Baglioni & $\begin{array}{c}\text { O pensamento, } \\
\text { imbuído de um } \\
\text { sentimento de } \\
\text { saudade e confusão, é } \\
\text { dirigido à pessoa } \\
\text { amada no sentido de } \\
\text { saber como e com } \\
\text { que ela está. }\end{array}$ \\
\hline RENAT & Più o meno & R. Zero & $\begin{array}{c}\text { Existe o temor de que } \\
\text { o amor termine. }\end{array}$ \\
\hline $\begin{array}{l}\text { PREMIATA FORNERIA } \\
\text { MARCONI }\end{array}$ & $\begin{array}{l}\text { Dolcissima } \\
\text { Maria }\end{array}$ & $\begin{array}{l}\text { F. Mussida, } \\
\text { F. F. Premoli, } \\
\text { M. Pagani }\end{array}$ & $\begin{array}{l}\text { Uma mulher cujos } \\
\text { sentimentos se } \\
\text { misturam alternando } \\
\text { sensações de solidão, } \\
\text { ansiedade, esperança e }\end{array}$ \\
\hline
\end{tabular}




\begin{tabular}{|c|c|c|c|}
\hline & & & fé no amanhã. \\
\hline PAOLO VALLESI & $\begin{array}{c}\text { La forza della } \\
\text { vita }\end{array}$ & $\begin{array}{l}\text { B. Dati } \\
\text { P. Vallesi }\end{array}$ & $\begin{array}{l}\text { A busca de uma } \\
\text { energia interior que } \\
\text { permita superar as } \\
\text { dificuldades } \\
\text { emocionais e } \\
\text { existenciais. }\end{array}$ \\
\hline \multirow[t]{3}{*}{ ALEANDRO BALDI } & $\begin{array}{l}\text { Il mondo degli } \\
\text { altri }\end{array}$ & A. Baldi & $\begin{array}{l}\text { O medo de se arriscar } \\
\text { no mundo frente à } \\
\text { possibilidade de } \\
\text { solidão. O amor } \\
\text { como elemento de } \\
\text { integração. }\end{array}$ \\
\hline & $\begin{array}{l}\text { Ti chiedo } \\
\text { onestà }\end{array}$ & A. Baldi & $\begin{array}{l}\text { O pedido de } \\
\text { transparência no } \\
\text { início de um } \\
\text { relacionamento. }\end{array}$ \\
\hline & Passerà & $\begin{array}{l}\text { A. Baldi } \\
\text { Bigazzi } \\
\text { Falagiani }\end{array}$ & $\begin{array}{l}\text { A música ajuda a } \\
\text { fazer passar as } \\
\text { pequenas tristezas e } \\
\text { os enganos } \\
\text { cotidianos. }\end{array}$ \\
\hline
\end{tabular}

Fig. 1. As canções italianas interpretadas por Renato Russo

A autora que Renato Russo mais interpreta é a pop star Laura Pausini cujas canções fazem com que ele passe a conhecer outros cantores como, por exemplo, Nino Bonocore. Quase todas as canções evidenciam a produção musical dos anos 1980/1990. O tema dominante é o amor em todas as suas diversas facetas, a saber:

- a esperança (Dolcissima Maria);

- a ansiedade e a revelação (Lettera) 
- o medo do abandono (Pì̀ o meno)

- o abandono (La solitudine, E tu come stai)

- a decisão de terminar um relacionamento (Strani amori)

- o pedido de sinceridade (Ti chiedo onestä)

- a lembrança (I venti del cuore)

Em algumas canções, existe uma solidão dolorosa: o amado experimenta o sofrimento da recordação em um contexto totalmente centrado no seu eu. Em alguns textos, o sentido de sofrimento pela ausência da pessoa amada é tão grande que só pode ser aliviado por uma aceno, ainda que seja para essa pessoa dizer que possui um novo amor (Scrivimi).

Outras considerações encontradas são as espaçosas reflexões sobre a relação entre o "eu e os outros" e entre o "eu e o mundo", busca de uma serenidade interior que pode ser determinada por várias coincidências:

- o poder consolador da música (Passera);

- a procura de uma força interior (La forz̧a della vita);

- o amor próprio (Il mondo degli altri);

- a decisão, quase espiritual, de captar as coisas e as emoções como aparecem; o gosto e o sabor da vida nada mais são do que uma consequência dessa decisão (La vita è adesso). 


\section{La vita è adesso e La forza della vita: retrato de duas Itálias}

É interessante, de um ponto de vista sociológico, perceber como uma mensagem análoga, que leva a ter fé na vida e a capturar a beleza que vem a cada dia, é transmitida em duas letras de músicas que retratam dois momentos tão diversos na Itália.

A primeira, La vita è adesso, de Claudio Baglioni, foi composta em meados dos anos 80: é autenticamente otimista e povoada por:

- imagens serenas, como conto de fadas, à moda de Fellini

la vita è adesso
nei pomeriggi appena freschi
che ti viene sonno
e le campane girano le nuvole
e piove sui capelli
e sopra i tavolini dei caffé all'aperto

a vida é agora

nas tardes apenas frescas

que te vem o sono

e os sinos viram nuvens

e chove sobre os cabelos

e sobre as mesas de café ao ar livre

- Apontamentos para a situação de solidão

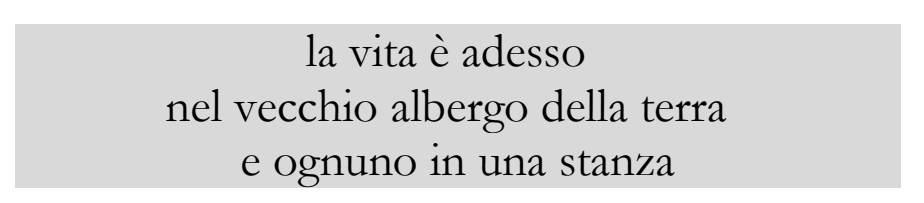

a vida é agora

no velho hotel da terra

e cada um em um cômodo 
- Pequenas "enquadraturas", ricas de criações lexicais brilhantes

e in una storia
di mattini più leggeri
e cieli smarginati di speranza
e di silenzi da ascoltare

e em uma bistória

de manhãs mais leves

e céus sangrados de esperança

e de silêncio para escutar

- de um sentimento de surpresa pela inexplicável sensação de felicidade

$$
\begin{gathered}
\text { e ti sorprenderai a cantare } \\
\text { ma non sai perché }
\end{gathered}
$$

e te surpreenderás a cantar

mas sem saber o porquê

(me vem em mente um dístico "ungarettiano": Tra un fiore colto e l'altro donato/ l'inesprimibile nulla - Entre uma flor cultivada e uma presenteada / o inexplicável nada).

Há ainda a presença de descrições rápidas e "frescas",

$$
\begin{gathered}
\text { nell'aria tenera di un dopocena } \\
\text { e musi di bambini } \\
\text { contro i vetri }
\end{gathered}
$$

no ar suave depois da janta

e rostos de crianças

contra os vidros 
acompanhadas por analogias curiosas ( $i$ prati che si lisciano come gattini), infantis, com verbos onomatopaicos selecionados (appicciano) e riquíssimas supressões (milioni):

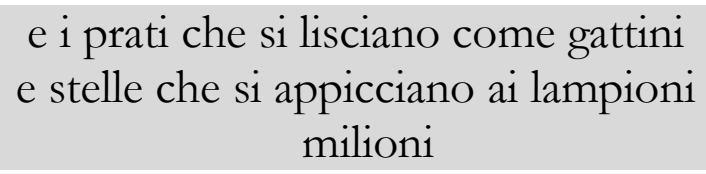

e os campos que se alisam como gatinhos e estrelas que se aplicam aos lampiões milhões

A Itália, naqueles anos, atravessava o segundo boom econômico: as grandes lacerações dos anos 70 são uma lembrança; o terrorismo é derrotado; ocorre a requalificação do Made in Italy nos mercados internacionais; o eixo Democracia Cristã-Socialistas no pentapartido inaugura uma época de relativa estabilidade; sucedem-se eventos de forte ressonância na memória coletiva como a vitória nos mundiais de futebol (Copa do Mundo) e a abertura dos arquivos da loja maçônica P2 dentre outros.

Com a segunda canção, La Forza della Vita, di Valesi, entramos, ao contrário, nos infelizes anos 90: a criminalidade organizada cresce sem medida; a máfia desencadeia fortes ataques ao Estado com as mortes dos juízes Falcone e Borsellino; a economia entra em uma fase de estagnação; grandes empresas, como a Fiat e a Olivetti perdem competitividade em nível internacional; a inflação sobe acima da média europeia; a distância que reside entre a classe de alta renda e a classe de baixa renda aumenta desmedidamente; os salários estão entre os mais baixos da Europa.

Várias outras canções invocam o passado com ar de nostalgia e meditação, dentre as quais se destaca Cosa resterà di quegli anni 80 ? 


Anni come giorni volati via
brevi fotogrammi o treni in galleria
è un effetto serra che scioglie la
felicità
delle nostre voglie e dei nostri jeans
che cosa resterà.
$[\ldots .$.
Noi siamo sempre più soli singole
metà
anni sui libri di scuola e poi a cosa
servirà.
$[\ldots .$.
Anni rampanti dei miti sorridenti da
wind-surf
sono già diventati graffiti ed ognuno
pensa a sé
forse domani a quest'ora non sarò
esistito mai
e i sentimenti che senti se ne andranno
come spray.
$[\ldots .$.
Anni veri di pubblicità, ma che cosa
resterà

Anos voaram como dias

breves fotolitos ou trens em túneis

é um efeito estufa que derrete a felicidade

dos nossos desejos e dos nossos jeans o que restará.

[...]

Nós estamos sempre mais solitários, individualistas anos sobre livros de escolas e depois para quê servirá [...]

Anos sem freio de mitos sorridentes de Wind-surf

já se transformaram em grafitte e cada um pensa em si 
talvez. amanhã a esta hora jamais terei existido

$e$ os seus sentimentos terão desaparecido como spray.

$[\cdots]$

Anos verdadeiros de publicidade, mas o que restará

anos alegres e depressivos de loucura e lucider.

já lembram os Anos Oitenta

para nós faz quase oitenta anos...

Nesses anos de trevas, as canções revoltadas e tristíssimas de Marco Masini tornaram-se letras de referência para as novas gerações. Paolo Vallesi, conterrâneo de Masini, queria se afirmar como contralto, falando de luz em um período de trevas, de renascimento em um período de grande depressão. $\mathrm{Na}$ realidade, ao falar da vida, Vallesi, através de B. Dati, que é quem escreve a letra da canção interpretada por Renato Russo, recorre a uma vasta coleção de imagens carregadas de sofrimento, demonstrando uma forte empatia com o estilo pessimista de Masini. Eis a primeira estrofe, na qual a palavra "força" caminha em um campo minado.

\footnotetext{
Anche quando ci buttiamo via per rabbia o per vigliaccheria per un amore inconsolabile anche quando in casa il posto è più invivibile e piangi e non lo sai che cosa vuoi credi c'è una forza in noi amore mio più forte dello scintillio di questo mondo pazzo e inutile è più forte di una morte incomprensibile e di questa nostalgia che non ci lascia mai.
} 


\author{
Mesmo quando jogamos fora \\ por raiva ou por covardia \\ por um amor inconsolável \\ mesmo quando em casa o lugar é mais inabitável \\ e você chora e não sabe o que quer \\ creia existe uma forç em nós meu amor \\ o brilho mais forte \\ deste mundo louco e inútil \\ é mais forte que uma morte incompreensivel \\ e do que esta nostalgia que não se perde nunca
}

É interessante notar, nos textos, como o sentimento de surpresa pela felicidade improvisada que aparece em Baglioni se contrapões a um sentimento de espanto pelo injustificável sofrimento (e piangi e non lo sai Che cosa vuoi) que é encontrado em Vallesi.

\title{
3. Literariedade das letras
}

Poucas são as letras, relativas às canções que Renato Russo interpretou, que se distinguem por qualidade literária.

As canções de Laura Pausini, por exemplo, são povoadas de metáforas pobres e gastas:

\section{Non siamo angeli in volo venuti dal cielo \\ Ma gente comune che ama davvero}

Não somos anjos em vôo vindos do céu mas gente comum que ama de verdade

por vezes demasiado próximas umas das outras para criar um trocadilho: 


\section{Marco se n'è andato e non ritorna più \\ Il treno delle 7:30 senza lui \\ È un cuore di metallo senza l'anima \\ Nel freddo del mattino grigio di città}

Marco se foi e não volta mais

O trem das $7 \mathrm{~h} 30$ sem ele

É um coração de metal sem alma

No frio da manhã cinzenta da cidade

Não muito diferente das canções de Laura Pausini são as de Renato Zero dentre as quais destacamos a canção Piú o meno, na qual os versos dificilmente seguem um critério racional, passando de alusões a Sócrates:

Più vivi e meno sai. / Quanto mais você vive, menos você sabe.

a banalidades óbvias:

Più spendi e meno hai.

Quanto mais você gasta, menos você tem.

e a fórmulas enigmáticas:

\section{Più o meno, sei qui.}

Mais ou menos, você está aqui.

A necessidade de uma rima imediata e fácil dá origem a uma letra que parece ingênua:

Se resti con me,

tornerò ad essere un re!

Se você fica comigo 


\section{Tornarei a ser um rei}

Em outras canções, como a melancólica Scrivimi, de Nino Bonocore, veem-se figuras retóricas mais ponderadas, como, por exemplo, uma bela descrição do outono:

Scrivimi...
quando il vento avrà spogliato gli
alberi

\section{Escreva-me...}

quando o vento houver despido as árvores

Na canção Il mondo degli altri, de Aleandro Baldi, há uma bem trabalhada descrição sobre uma tarde passada em solidão, na qual todos parecem parar e o céu é personificado:

\section{Alle tre di pomeriggio sto seduto sui gradini \\ Mentre il cielo si fa pigro e si riposa sui camini}

Às três horas da tarde estou sentado nos degraus

Enquanto o céu se espreguiça e repousa sobre as lareiras

Um par de oxímoros distribuídos respectivamente em Strani amori, cantada por Laura Pausini, e Passerà, cantada por Aleandro Baldi, são uma chave eficaz para entrar na psicologia tanto das relações afetivas que não buscam mais qualquer prazer 
Estranhos amores frágeis, prisioneiros livres

quanto no estado de temor de quem, embora desfrutando de um certo bem estar, parece vítima de alguma inquietação.

e le angosce di una ricca povertà

$e$ as angústias de uma rica pobreza

Certamente a música que mais se destaca por equilíbrio e composição formal é I venti del cuore (escrita por Massimo Bubola e interpretada por Fiorella Mannoia) na qual estão presentes descrições em cores vivas de lugares e objetos passados:

Campi di lavanda e l'auto che va dietro quei cipressi la strada piegherà

e passata la collina chissà

se la casa come un tempo mi apparirà

Campos de lavanda e o carro que vai

Atrás daqueles ciprestes a estrada dobrará

E passada a colina, quem sabe

Se a casa como um tempo me aparecerá

Até mesmo as recordações mais nítidas, como as contidas nos seguintes versos que indicam uma lembrança feliz

quanti bimbi e cani avevi intorno

e che chiasso di colori al tramonto

quantas crianças e cães haviam em torno

e que ruidos de cores ao pôr do sol 
aparecem, todavia, envoltas em dúvida como demonstram o versos seguintes:

$$
\begin{gathered}
\text { le memorie poi s'increspano } \\
\text { e non so più chi sei }
\end{gathered}
$$

as memórias depois se confundem

e eu não sei mais quem és

Alguns versos contêm imagens animadas que nos remetem a uma infância encantada, vista como se fosse um álbum fotográfico através do qual o autor questiona o sentido da própria identidade:

\footnotetext{
E mi sembrava quasi un'eternità che non salivo scalza sopra quel glicine in penombra ti guardavo dormire nei capelli tutti i nidi d'aprile$$
\text { ...e le immagini si perdono }
$$$$
\text { fermarle non potrei }
$$$$
\text { e le pagine non svelano }
$$$$
\text { chi eri e chi ora sei }
$$

E me parecia quase uma eternidade

que não subia descalça sobre aquela glicínia

na penumbra te observava a dormir

nos cabelos todos os ninhos de abril

[...]

...e as imagens se perdem

pará-las eu não poderia

$e$ as páginas não revelam

quem eras e quem és agora
} 


\section{Conclusão}

Não nos é possível saber, de fato, quais foram as razões que conduziram Renato Russo a selecionar as canções italianas, apresentadas nesse artigo, e incluílas em seu repertório. Ele escolheu tanto cantores mundialmente reconhecidos, Laura Pausini, como outros menos notados no exterior, negligenciando, em alguns casos, as considerações da literariedade das letras, como exemplo podemos citar a canção Più o meno. Renato Russo demonstrou-se indiferente com o fato de incluir no repertório grupos em declínio no panorama musical italiano La Premiata Foneria Marconi, grupo em auge nos anos 70 que já estava à beira do anonimato na década seguinte.

É surpreendente notar que Renato Russo recuperou Aleandro Baldi, um autor entre os mais refinados e brilhantes daqueles anos, e constatar proximidades entre ambos, tanto pela sensibilidade quanto pela vivência pessoal - é como se a cegueira de um criasse um limite em relação à dificuldade de deambular do outro. Na verdade, é ouvindo de novo os sons menos conhecidos de Baldi, como a belíssima canção Il mondo degli altri, que alcançou pouco sucesso na Itália, que um italiano, hoje, pode reavaliar esse autor, aclamado entre as décadas de 80 e 90 - vencedor de dois prêmios do Festival de SanRemo, um na categoria giovane e outro na categoria big. Apesar do sucesso alcancado, ele sumin misteriosamente, caindo no mais cruel esquecimento (sobre Baldi, o mercado discográfico italiano disse que dois cegos seria demais: teriam que promover Bocelli ou ele). 